Review Article

\title{
Speciation in Solutions of Lithium Salts in Dimethyl Sulfoxide, Propylene Carbonate, and Dimethyl Carbonate from Raman Data: A Minireview
}

\author{
M. I. Gorobets, ${ }^{1}$ M. B. Ataev, ${ }^{2}$ M. M. Gafurov, ${ }^{2}$ and S. A. Kirillov ${ }^{1}$ \\ ${ }^{1}$ Joint Department of Electrochemical Energy Systems, 38 A Vernadsky Ave., Kyiv 03142, Ukraine \\ ${ }^{2}$ Kh. I. Amirkhanov Institute of Physics and Analytical Center of Common Access, 94 M. Yaragsky St., Makhachkala 367003, Russia
}

Correspondence should be addressed to S. A. Kirillov; kir@i.kiev.ua

Received 19 August 2016; Accepted 10 October 2016

Academic Editor: Christoph Krafft

Copyright (C) 2016 M. I. Gorobets et al. This is an open access article distributed under the Creative Commons Attribution License, which permits unrestricted use, distribution, and reproduction in any medium, provided the original work is properly cited.

Our recent Raman studies of cation and anion solvation and ion pairing in solutions of lithium salts in dimethyl sulfoxide, propylene carbonate, and dimethyl carbonate are briefly overviewed. Special attention is paid to differences in our and existing data and concepts. As follows from our results, cation solvation numbers in solutions are low $(\sim 2)$ and disagree with previous measurements. This discrepancy is shown to arise from correct accounting for dimerization, hydrogen bonding, and conformation equilibria in the solvents disregarded in early studies. Another disputable question touches upon the absence of free ions in solutions of lithium salts in carbonate solvents and the statement that the charge transfer in carbonate solutions is caused by SSIPs. Direct proofs of the nature of charge carriers in the solvents studied have been obtained by means of analyses of vibrational dynamics. It has been found that collision times for free anions are short and evidence weak interactions between anions and solvent molecules. In SSIPs, collision times are an order of magnitude longer thus signifying strong interactions between anions and cations. In CIPs, collision times become shorter than in SSIPs reflecting the transformation of the structure of concentrated solutions to that of molten salts.

\section{Introduction}

Due to its sensitivity to molecular interactions between functional groups of molecules and ions, vibration spectroscopy is perhaps the most powerful tool for studying speciation in nonaqueous solutions. This problem has been actively pursued in the past [1] and now is of great interest for nonaqueous electrolytes employed in lithium-ion batteries [2]. It is especially valuable to know the composition and structure of particles, that is, solvated cations, solvated anions, and various kinds of associates including solvent separated ion pairs (SSIPs), contact ion pairs (CIPs), and more complex aggregates present in solutions, because their formation and reactivity are considered to determine the creation of solid electrolyte interfaces emerging upon charge/discharge processes in batteries. In the case of battery electrolytes, experimentalists are deprived of opportunities to select simplest model solvents, so as to make the changes accompanying solvation more vivid, and are forced to operate with quite complex real systems. It should be mentioned that their own equilibria caused by hydrogen bonding, isomerisation, and so forth in the solvents employed in batteries are usually present. It makes spectroscopic studies of speciation in battery electrolytes a formidable task.

In our recent papers [3-7] we have described phase diagrams, conductivity, and Raman spectra of solutions of six lithium salts, namely, lithium tetrafluoroborate $\mathrm{LiBF}_{4}$, perchlorate $\mathrm{LiClO}_{4}$, bis(oxalato) borate $\mathrm{LiB}\left(\mathrm{C}_{2} \mathrm{O}_{4}\right)_{2}$, trifluoromethylsulfonate $\mathrm{LiCF}_{3} \mathrm{SO}_{3}$, nitrate $\mathrm{LiNO}_{3}$, and bis(trifluoromethylsulfonyl) imide $\mathrm{LiN}\left(\mathrm{CF}_{3} \mathrm{SO}_{3}\right)_{2}$ in a concentration range from 0.05 to 0.25 mole fractions of a salt (from diluted solutions to the mixtures of molten $\mathrm{LiX} \cdot 4 \mathrm{~S}$ solvates with $\mathrm{LiX}$, where $\mathrm{X}$ is the anion) in three solvents, dimethyl sulfoxide, $\left(\mathrm{CH}_{3}\right)_{2} \mathrm{SO}$ (DMSO), propylene carbonate, $\mathrm{C}_{4} \mathrm{H}_{6} \mathrm{O}_{3}(\mathrm{PC})$, and dimethyl carbonate, $\mathrm{C}_{3} \mathrm{H}_{6} \mathrm{O}_{3}$ (DMC). All these salts and solvents are employed in industrial and laboratory practice. Salt solutions in various mixtures of PC and DMC and DMC's fluorinated variety are 
readily available on the market as the solvents for commercial lithium-ion batteries. DMSO is a prospective solvent for lithium-oxygen batteries [8-10]. Special attention has been paid to equilibria in the solvent studied. In DMSO $[11,12]$ and DMC [13], these include dipole-dipole interactions between molecules. In PC, one should account for both dipole-dipole interactions and hydrogen bonding $[14,15]$.

As far as speciation in DMSO solutions is concerned, signatures of cationic solvation have been characterized in precious studies [16-19] and up to four DMSO molecules have been found to form the solvation sphere of the $\mathrm{Li}^{+}$ion interacting with it through the negatively charged oxygen atom of the $\mathrm{S}=\mathrm{O}$ group. This solvation number might be corrected since DMSO is an ordered, associated liquid but dimerization equilibria have not been taken into account in solvation studies. In PC solutions, solvation is visible spectroscopically as an interaction of the $\mathrm{Li}^{+}$ions with the oxygen atom of the $\mathrm{C}=\mathrm{O}$ group $[20,21]$. This leads to the decomposition of dimers existing in this associated and hydrogen bonded liquid [22]. The solvation number varies from 4 to 2 when the concentration of the solution grows [23-25]. Spectroscopic studies of solvation in DMC, which is considered neither ordered nor hydrogen bonded, have shown that solvation of the $\mathrm{Li}^{+}$ions strongly influences conformation equilibria stabilizing the cis-trans conformer [26]. The solvation numbers determined by spectroscopic methods are equal to 4 [26].

Cation solvation is usually described in terms of electrostatic attraction, whereas anion solvation is considered to arise either from electrostatic attraction between positively charged hydrogen atoms of the methyl groups of a solvent and oxygen or fluorine atoms of an anion or from hydrogen bonding between them. Anion solvation in solutions of lithium salts in DMSO manifests itself in Raman spectra in the region of stretching $\mathrm{CH}_{3}$-vibrations as an upshift and broadening of respective lines signifying interactions between anions and solvent molecules [18, 19, 27]. In PC solutions, signatures of anion solvation are less definite [22], and spectroscopic manifestations of anion solvation in DMC solutions have not been reported.

Ion pairing in electrolyte solutions is showing up as an uprise of extra lines in the region of stretching vibrations of anions. For example, upon adding $\mathrm{LiClO}_{4}$ and $\mathrm{LiNO}_{3}$ to DMSO, new lines appear on the high-frequency side of the lines corresponding to the totally symmetric $\nu_{1}\left(\mathrm{~A}_{1}\right) \mathrm{Cl}-\mathrm{O}$ and $v_{1}\left(\mathrm{~A}_{1}^{\prime}\right) \mathrm{N}-\mathrm{O}$ vibrations of anions. For perchlorates, the line at $933 \mathrm{~cm}^{-1}$ is assigned to free, unperturbed $\mathrm{ClO}_{4}{ }^{-}$anions, the line at $938-939 \mathrm{~cm}^{-1}$ belongs to anions in SSIPs [28], and that at $944-946 \mathrm{~cm}^{-1}$ reflects the presence of CIPs where perturbations of the anion are the strongest [29, 30]. Line shifts for nitrates $[16,31,32]$ and trifluoromethylsulfonates [17] are similar. The data on ion pairing of $\mathrm{BF}_{4}{ }^{-}$ions are much scarce $[33,34]$. Bis(trifluoromethylsulfonyl) imide anion in solutions exists in the form of cis- and trans-conformers, the latter being more stable $[35,36]$. The most intense Raman line at $740 \mathrm{~cm}^{-1}$ corresponds to the symmetric bending $\delta_{\mathrm{s}}\left(\mathrm{A}_{1}\right)$ $\mathrm{CF}_{3}$ vibrations and is convenient for studying ion pairing phenomena $[37,38]$. For examining ion pairing phenomena in bis(oxalato) borates, the line at $724 \mathrm{~cm}^{-1}$ corresponding to the symmetric $\delta_{\mathrm{s}}\left(\mathrm{A}_{1}\right)$ O-B-O bending has been recommended [39].

Signatures of ion pairing in $\mathrm{PC}$ are recognized in systems containing $\mathrm{ClO}_{4}{ }^{-}[20,22], \mathrm{BF}_{4}{ }^{-}[24], \mathrm{N}\left(\mathrm{SO}_{3} \mathrm{CF}_{3}\right)_{2}{ }^{-}$[40], and $\mathrm{CF}_{3} \mathrm{SO}_{3}{ }^{-}$[41] anions. Some of this data are controversial. In particular, Aroca and coworkers have shown that, in $\mathrm{LiClO}_{4}-\mathrm{PC}$ solutions, the line at $933 \mathrm{~cm}^{-1}$ corresponds to free $\mathrm{ClO}_{4}{ }^{-}$anions, the line at $938 \mathrm{~cm}^{-1}$ belongs to SSIPs, and that at $944 \mathrm{~cm}^{-1}$ reflects the presence of CIPs. Brooksby and Fawcett disagree with this assignment considering that, in $\mathrm{NaClO}_{4}$-PC solutions, the line corresponding to free $\mathrm{ClO}_{4}{ }^{-}$ anions, SSIPs and CIPs manifest themselves at 930, 933, and $938 \mathrm{~cm}^{-1}$, respectively [22]. As far as DMC solutions are concerned, free anions, SSIPs, CIPs, and even more complex aggregates are detected in the $\mathrm{LiAsF}_{6}$-DMC system [26].

In [3-7], speciation in DMSO, PC, and DMC solutions of lithium salts has been first described explicitly, with no arbitrary assumptions, in a single experiment. Solvated cations, anions, SSIPs, and CIPs have been detected, and their concentrations have been determined with due regard for equilibria existing in the solvents. In this paper, we briefly overview this data with special emphasis on differences in our and existing concepts. Specifically, we put forward an explanation of low cation solvation numbers in solutions and emphasize that they originate from correct accounting for association processes in the solvents studied. Secondly, we show that differences in the concentrations of CIPs in solutions of different salts can be understood in terms of ion pairs dissociation energy obtained by means of quantum chemical calculations. Finally, we suggest that solvation equilibria in solutions are significantly determined by the donor numbers of solvents.

\section{Experimental Details}

Lithium salts and solvents, preliminary operations with them, their quality control, and the preparation of solutions are described in [4]. Raman spectra were excited by the $532 \mathrm{~nm}$ line of a solid state (Nd:YAG) laser and registered at Analytical Center of Common Access, Dagestan Scientific Center of the Russian Academy of Sciences, Makhachkala, on a confocal Raman microscope (Senterra, Bruker, Germany) with a $20 \mathrm{x}$ camera lens, the slit of $50 \times 100 \mathrm{mkm}$, and resolution of $3 \mathrm{~cm}^{-1}$. At least 20 scans were accumulated at polarized $\left(I_{\mathrm{VV}}\right)$ and depolarized $\left(I_{\mathrm{VH}}\right)$ scattering geometries with the integration time of $20 \mathrm{~s}$. The first and the second letters in subscripts denote the state of polarization of the incident and scattered radiation, respectively; $\mathrm{V}$ stands for vertical and $\mathrm{H}$ for horizontal. Knowing $I_{\mathrm{VV}}(\nu)$ and $I_{\mathrm{VH}}(\nu)$, where $v$ is the running wavenumber, the so-called isotropic and anisotropic line profiles were calculated as

$$
\begin{aligned}
I_{\text {iso }}(\nu) & =I_{\mathrm{VV}}(\nu)-\frac{4}{3} I_{\mathrm{VH}}(\nu), \\
I_{\text {aniso }}(\nu) & =I_{\mathrm{VH}}(\nu) .
\end{aligned}
$$

Since all the lines studied are sharply polarized only isotropic spectra are presented in what follows. 
Solvation phenomena and ion pairing perturb the molecules of solvents and anions are showing up in Raman spectra as appearance of new lines corresponding to vibrations of new structural entities. These new lines are situated in a close proximity to the lines of unperturbed particles resulting in composite lines. Their decomposition has been performed by a method described in [42] where experimental spectra are modelled by the sum of the following expressions:

$$
I(\nu)=\frac{2 n c \exp \left(\tau_{1} / \tau_{2}\right)\left(\tau_{1}^{2} / \tau_{2}\right) K_{1}(x)}{x}
$$

where $x=\tau_{1}\left[4 \pi^{2} c^{2}\left(\nu-v_{0}\right)^{2}+1 / \tau_{2}^{2}\right]^{1 / 2}, n=2$ if $\nu_{0}=0$ and $n=1$ if $v_{0} \neq 0, c$ is the speed of light, $v_{0}$ is the wavenumber of the line maximum, $\tau_{1}$ and $\tau_{2}$ are certain parameters, and $K_{1}(x)$ is the modified Bessel function of the second kind. This expression is more flexible than the commonly used Voight function and is widely used for the decomposition of overlap lines [43]. In order to find the dependence of the amount of particles present in solutions on the concentration of lithium salts, $c_{i}=f\left(c_{\text {salt }}\right)$, it was considered that $c_{i}$ values are proportional to integrated intensities of isotropic lines. As no data exist regarding scattering abilities of particles in the free state, solvation sphere, SSIPs, and CIPs, their possible differences at the present state of our knowledge were disregarded.

We skip any detailed description of the vibrational spectra of pure DMSO, PC, and DMC; it can be found in [4446]. In all spectra processing procedures, we account for the presence of all lines in the investigated regions. For the sake of simplicity, in figures, we give calculation results for the lines directly involved in interparticle interactions (see explanations below) and do not talk over changing parameters of other lines visible in selected spectral windows.

\section{Results and Discussion}

3.1. Spectroscopic Signatures of Solvation. On adding lithium salts the Raman spectra of solvents undergo changes, namely, the shift and broadening of the lines studied occur, and new lines emerge as a result of solvation. Representative Raman spectra reflecting cation solvation are given in Figure 1 together with their fits. A composite line in the region of $v_{10}$ $\left(\mathrm{A}^{\prime}\right)$ symmetric CSC stretch vibration can be decomposed to three component lines, corresponding to the monomeric $\left(\nu_{\text {iso }}=663-670 \mathrm{~cm}^{-1}\right)$, dimeric $\left(\nu_{\text {iso }}=667-669 \mathrm{~cm}^{-1}\right)$, and solvating $\left(\nu_{\text {iso }}=674-676 \mathrm{~cm}^{-1}\right)$ DMSO molecules. In the case of $\mathrm{PC}$, the line corresponding to $v_{10}\left(\mathrm{~A}_{1}\right)$ breathing ring vibration can be decomposed to three component lines characteristic of the monomeric $\left(\nu_{\text {iso }}=706-707 \mathrm{~cm}^{-1}\right)$, dimeric $\left(v_{\text {iso }}=711-712 \mathrm{~cm}^{-1}\right)$, and solvating $\left(v_{\text {iso }}=716-717 \mathrm{~cm}^{-1}\right)$ PC molecules. In DMC solutions, the line corresponding to $v_{9}\left(\mathrm{~A}_{1}\right)$ OCO deformations can also be decomposed to three component lines characteristic of the monomeric $\left(\nu_{\text {iso }}=\right.$ $\left.513-515 \mathrm{~cm}^{-1}\right)$, dimeric $\left(\nu_{\text {iso }}=516-517 \mathrm{~cm}^{-1}\right)$, and solvating $\left(\nu_{\text {iso }}=523 \mathrm{~cm}^{-1}\right)$ DMC molecules.

Anion solvation manifests itself in changes in Raman spectra shown in Figure 2. Decomposition of the spectra of lithium salt solutions in DMSO in the region of $v_{3}$
$\left(\mathrm{A}^{\prime}\right) \mathrm{CH}$ stretching vibration gives two component lines. Concentration dependence of their intensities reveals that the high-frequency component $\left(\sim 2919 \mathrm{~cm}^{-1}\right)$ corresponds to the nonbonded DMSO molecules, whereas the low-frequency one $\left(\sim 2913 \mathrm{~cm}^{-1}\right)$ belongs to the solvent molecules entering the solvation sphere of the anion and hydrogen bonded to them.

Upon adding the salt, the overall PC line corresponding to $v_{14}\left(\mathrm{~A}_{1}\right) \mathrm{CH}$ stretching vibrations is changing insignificantly. However, the concentration dependence of data fits reveals that, on rising concentration, clear redistribution of intensity between the low- and high-frequency components takes place. As the high-frequency component $\left(\sim 2941 \mathrm{~cm}^{-1}\right)$ increases and the low-frequency component $\left(\sim 2930 \mathrm{~cm}^{-1}\right)$ decreases in intensity one can be confident that the former belongs to the PC molecules entering the solvation sphere of the anion and hydrogen bonded to them, whereas the latter reflects the presence of the nonbonded solvent molecules.

In DMC solutions, the behavior of $v_{2}\left(\mathrm{~A}_{1}\right) \mathrm{CH}$ stretching vibration in the salt solutions in DMC is similar to that of $\mathrm{CH}$ vibration in DMSO solutions. Splitting of the line occurs and, in accord with concentration dependence, the split lines can be assigned to the low-frequency component $\left(\sim 2919 \mathrm{~cm}^{-1}\right)$ corresponding to the nonbonded DMC molecules and the high-frequency one $\left(\sim 2913 \mathrm{~cm}^{-1}\right)$ belonging to the solvent molecules, which enter the solvation sphere of the anion and are hydrogen bonded to them.

Intensity measurements enable one to find the dependence of the amount of particles present in solutions on the concentration of lithium salts $\operatorname{LiX}, c_{i}=f\left(c_{\text {salt }}\right)$. Using these concentration dependencies one can calculate $\bar{n}_{i}$, the mean number of the solvent molecules bonded to cations and anions (solvation number, coordination number, or the socalled Bjerrum function), as

$$
\bar{n}_{i}=\frac{c_{i}}{c_{\text {salt }}}
$$

where $c_{i}$ is the equilibrium concentration of the solvent molecules bonded to $i$ th ion and $c_{\text {salt }}$ is the total concentration of the salt. It appears that, for cations, $\bar{n}_{i}$ values are almost independent on concentration being equal to ca. 2 (Figure 3 ). This value is much less than that usually obtained in other works. The reason for such discrepancy lies in the fact that, in previous investigations $[17,19]$, no equilibria in the solvents, dimerization equilibrium on the first place, have been taken into account. In this case, Raman spectra similar to that shown in Figure 1 are decomposed into two lines instead of three lines in our works; that is, the solvent spectrum is modelled with two lines corresponding to nonsolvating and solvating molecules. Differences in fits with three and two lines under the envelope of a composite line have been analyzed in [4]. Representative data are shown in Figure 4. Differences between experimental and calculated intensities (Figure 4, lover panels) visually signify that the threeline fit better reflects reality. Respective statistics (Table 1) support this statement. This means that disregarding possible equilibria in solvents may lead to a significant increase in the 

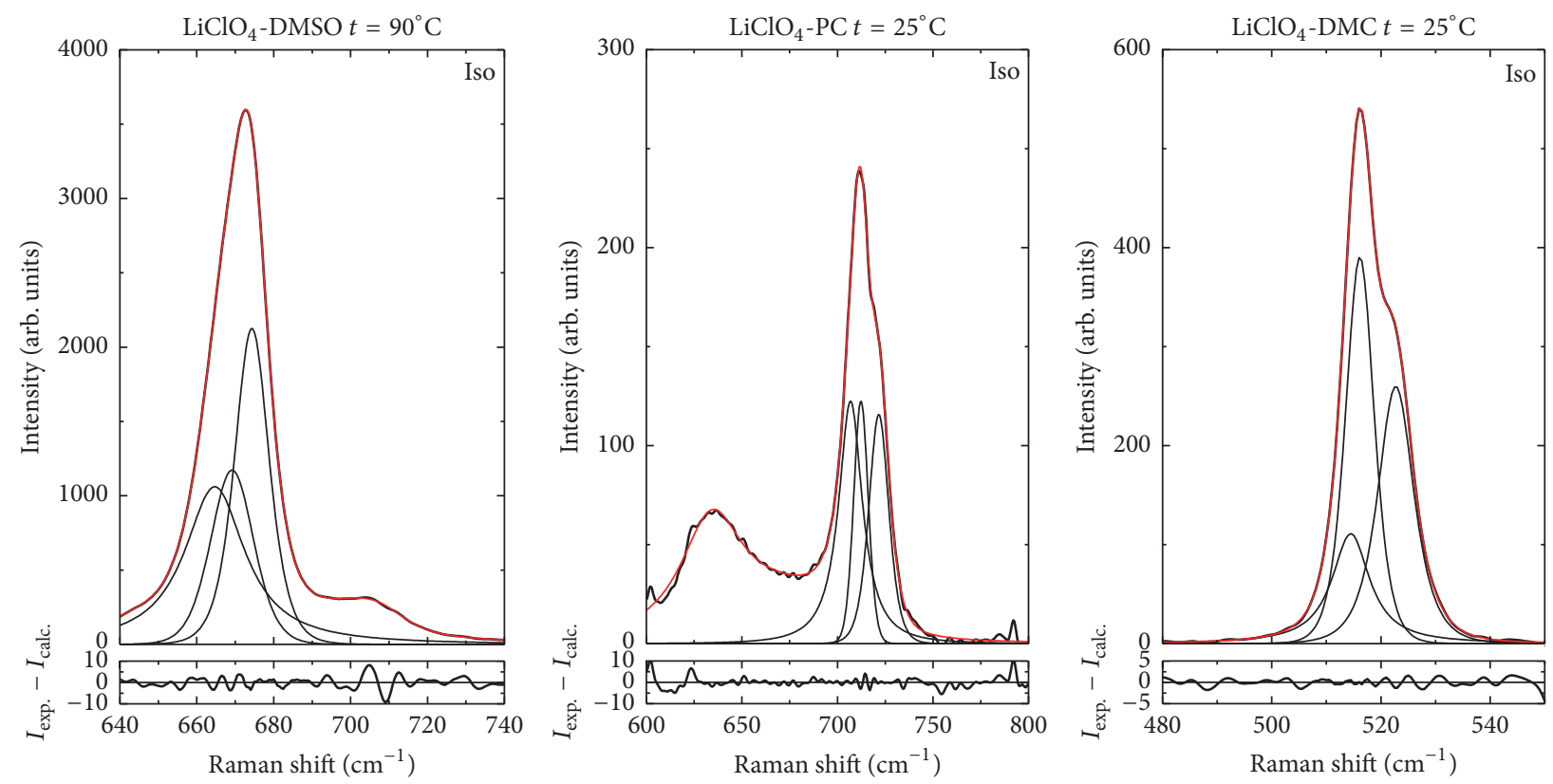

FIGURE 1: Raman spectra of DMSO, PC, and DMC solutions containing 0.15 mole fractions of $\mathrm{LiClO}_{4}$ in regions sensitive to cation solvation effects.
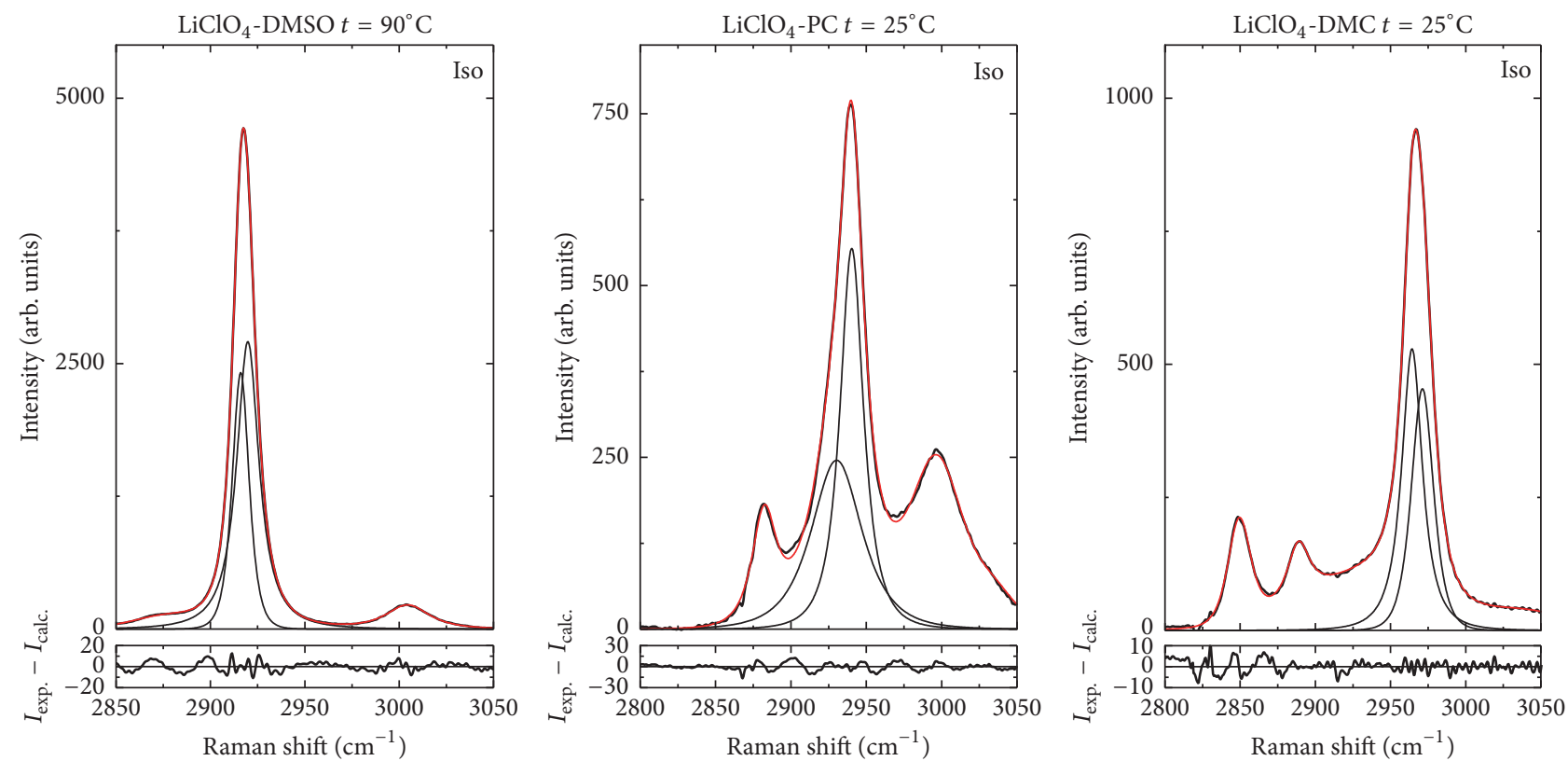

FIGURE 2: Raman spectra of DMSO, PC, and DMC solutions containing 0.15 mole fractions of $\mathrm{LiClO}_{4}$ in the region sensitive to anion solvation effects.

estimated concentration of solvated ions and hence to higher (i.e., mistaken) solvation number values.

Unlike cations, the mean coordination number of anions significantly depends on concentration and varies within wide limits (Figure 5).

3.2. Spectroscopic Signatures of Ion Pairing. Signatures of ion pairing in solutions are showing up first of all as extra lines appearing in the vicinity of intense lines corresponding to nondegenerated vibrations of anions. For example, adding $\mathrm{LiBF}_{4}$ to DMSO splits $v_{1}$ line of $\mathrm{BF}_{4}{ }^{-}$into three components at 760,763 , and $768 \mathrm{~cm}^{-1}$, which can be assigned to anions in the free state, in SSIPs, and in CIPs, respectively (Figure 6). Evolution of the integrated intensities of the component lines enabling one to find the concentrations of free anions and ion pairs in all solutions studied is shown in Figure 7. The data for nitrate solutions are not presented because the spectra 

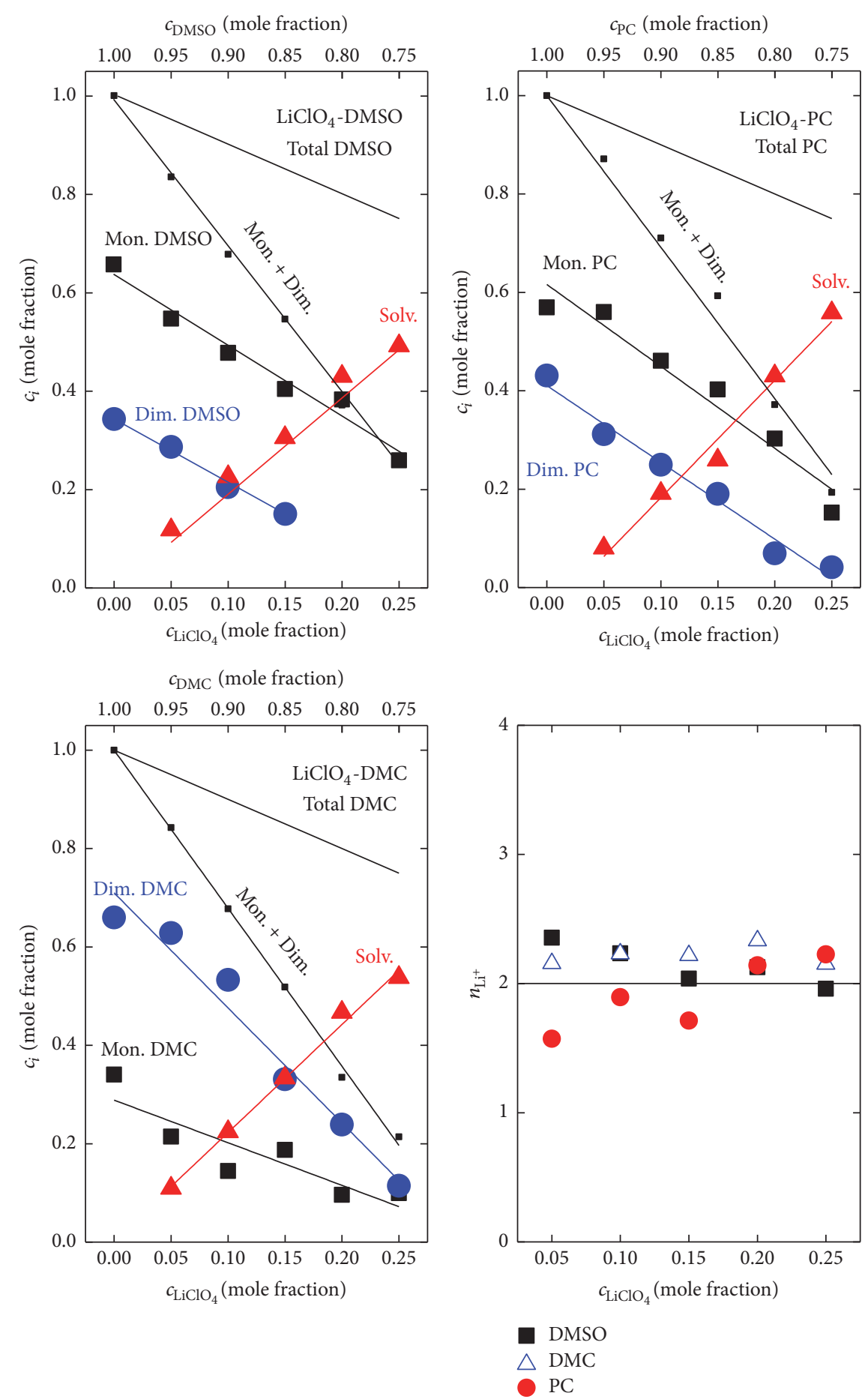

Figure 3: Concentration dependence of the amounts of monomeric, dimeric, and solvating molecules of the solvent and mean number of the solvent molecules bonded to cations in ionic solutions of DMSO, PC, and DMC.

of $\mathrm{NO}_{3}{ }^{-}$and the solvent overlap severely and cannot be decomposed.

As follows from the data presented in Figure 7, the concentration of CIPs in DMSO solutions of lithium salts decreases in the following order of anions: $\mathrm{BF}_{4}{ }^{-}>\mathrm{ClO}_{4}{ }^{-} \approx$ $\mathrm{CF}_{3} \mathrm{SO}_{3}{ }^{-}>\mathrm{N}\left(\mathrm{SO}_{3} \mathrm{CF}_{3}\right)_{2}^{-}=\mathrm{B}\left(\mathrm{C}_{2} \mathrm{O}_{4}\right)_{2}{ }^{-}=0$. Interestingly, dissociation energies of ion pairs $\mathrm{Li}^{+} \mathrm{A}^{-}$obtained by means of quantum chemical calculations (B3LYP/6-311+G* method) can be arranged in the same order (Table 2). This means that a minimal potential energy of pairwise interactions exists $\left(580 \mathrm{~kJ} \mathrm{~mol}^{-1}\right)$, below which contact ion pairs in DMSO solutions of lithium salts cannot be formed, and the amount of CIPs in solutions of salts in DMSO is determined by the dissociation energy of contact ion pairs. If these 

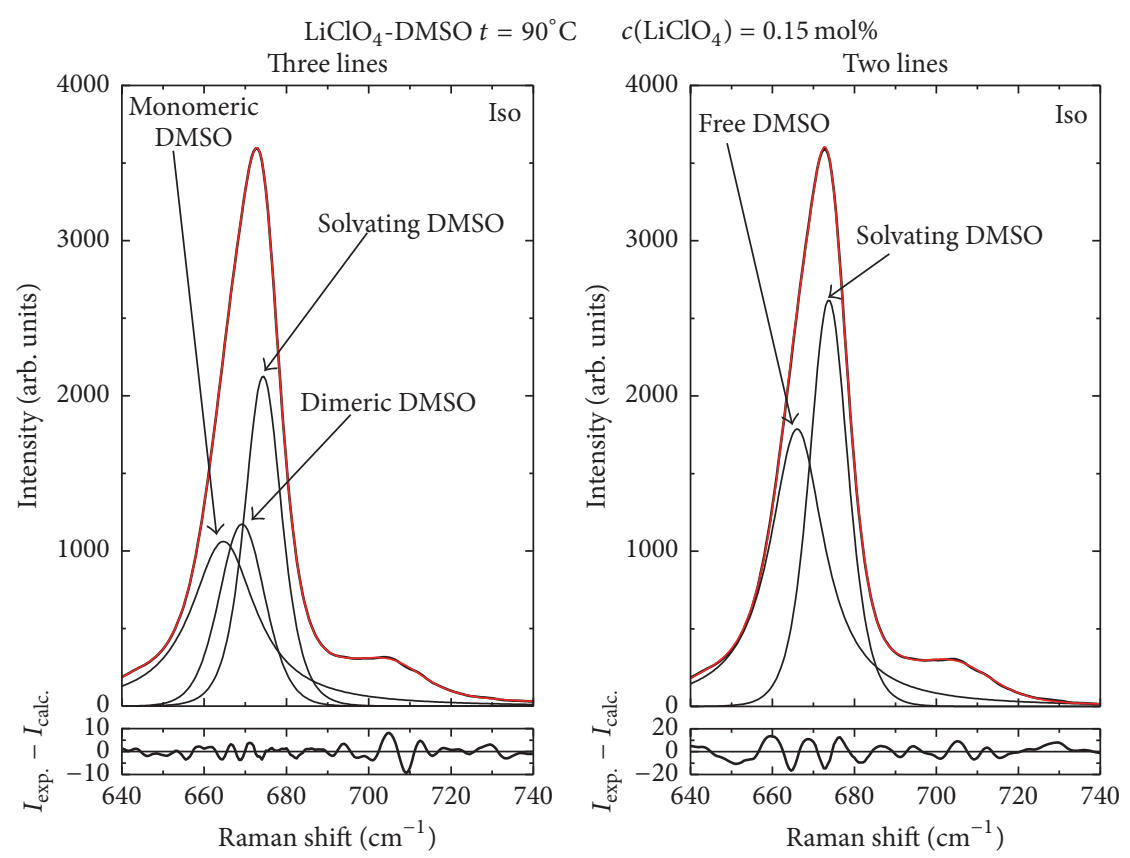

FIGURE 4: Representative example of data fits with (three lines) and without (two lines) distinguishing between monomeric and dimeric molecules of the solvent in the DMSO solution containing 0.15 mole fractions of $\mathrm{LiClO}_{4}$.

TABLE 1: Computation results obtained with (three lines) and without (two lines) distinguishing between monomeric and dimeric molecules of the solvent in the DMSO solution containing 0.15 mole fractions of $\mathrm{LiClO}_{4}$.

\begin{tabular}{lcc}
\hline Parameters of fits & Three lines & Two lines \\
\hline$v_{1}$ & 664.7 & 666.02 \\
$v_{2}$ & 669.2 & \\
$v_{3}$ & 674.3 & 673.73 \\
Best weighted sum of squares & $3.6557 \times 10^{3}$ & $1.0218 \times 10^{4}$ \\
Weighted root mean square error & 3.7212 & 6.2452 \\
Weighted deviation fraction & $1.0756 \times 10^{-3}$ & $3.6318 \times 10^{-3}$ \\
$R^{2}$ & 0.99998 & 0.99996 \\
\hline
\end{tabular}

TABLE 2: Ion pair $\mathrm{Li}^{+} \mathrm{A}^{-}$dissociation energy obtained by means of quantum chemical calculations [50].

\begin{tabular}{lc}
\hline Anion & Ion pair dissociation energy, $\mathrm{kJ} \mathrm{mol}^{-1}$ \\
\hline $\mathrm{NO}_{3}{ }^{-}$ & 653 \\
$\mathrm{BF}_{4}{ }^{-}$ & 602 \\
$\mathrm{ClO}_{4}{ }^{-}$ & 594 \\
$\mathrm{CF}_{3} \mathrm{SO}_{3}{ }^{-}$ & 594 \\
$\mathrm{~N}_{\left(\mathrm{SO}_{3} \mathrm{CF}_{3}\right)_{2}{ }^{-}}$ & 580 \\
$\mathrm{~B}\left(\mathrm{C}_{2} \mathrm{O}_{4}\right)_{2}{ }^{-}$ & 521 \\
\hline
\end{tabular}

considerations are correct, nitrate solutions in DMSO can be suspected to contain the maximal concentration of CIPs.

In [5], significant efforts have been undertaken so as to understand the Raman spectra of solutions of $\mathrm{LiClO}_{4}$ in DMSO, PC, and DMC. In [28-30], the lines at 929, 932, and $937 \mathrm{~cm}^{-1}$ showing up in the $\mathrm{LiClO}_{4}$-DMSO system are attributed to anions in free state, in SSIPs, and in CIPs, respectively. The similar treatment of the split lines for the $\mathrm{NaClO}_{4}$-DMSO system has been made by Brooksby and Fawcett [22] and that for $\mathrm{LiClO}_{4}-\mathrm{H}_{2} \mathrm{O}$ nanodroplets has been made by Guo et al. [47]. In the carbonate solvents, data fits clearly reveal the presence of two types of $\mathrm{ClO}_{4}{ }^{-}$-containing particles with the lines at $v=932.5$ and $937 \mathrm{~cm}^{-1}$ in PC and at $v$ $=933$ and $942 \mathrm{~cm}^{-1}$ in DMC. Comparing this finding with the results obtained for DMSO solutions, one may suppose that, in PC and DMC, free anions are absent, and only SSIPs and CIPs are showing up in Raman. On the other hand, Battisti and coworkers [20] preferred to assign the low-wavenumber lines to the free $\mathrm{ClO}_{4}{ }^{-}$and the high-wavenumber lines to the anions in SSIPs.

In order to discern between these two assignments, the conductivity data [3] appear to be helpful. If one follows the assignment performed by Battisti and coworkers [20] and considers that the perchlorate lines at 932.5 and $937 \mathrm{~cm}^{-1}$ in PC and at 933 and $942 \mathrm{~cm}^{-1}$ in DMC correspond to the free anions and SSIPs, respectively (Assignment 1 in Figures 7(f) and $7(\mathrm{~g})$ ), the order of solvents for increasing concentration of free anions is $\mathrm{PC}<\mathrm{DMSO}<\mathrm{DMC}$ and that for decreasing concentration of SSIPs is PC $>$ DMSO $>$ DMC. Such orders have nothing to do with the order of solvents for increasing conductivity DMC $<\mathrm{PC} \ll \mathrm{DMSO}$ [3]. If one considers that the lines at $932.5(\mathrm{PC})$ and $933 \mathrm{~cm}^{-1}$ (DMC) belong to SSIPs and those at 937 (PC) and $942 \mathrm{~cm}^{-1}$ (DMC) to CIPs (Assignment 2 in Figures 7(f) and 7(g)), the presence of free anions in PC and DMC should be excluded in the whole concentration range studied. Such consideration leads to the order of solvents for increasing concentration of free anions as $\mathrm{PC}=\mathrm{DMC}(=0) \ll \mathrm{DMSO}$ and that for decreasing 

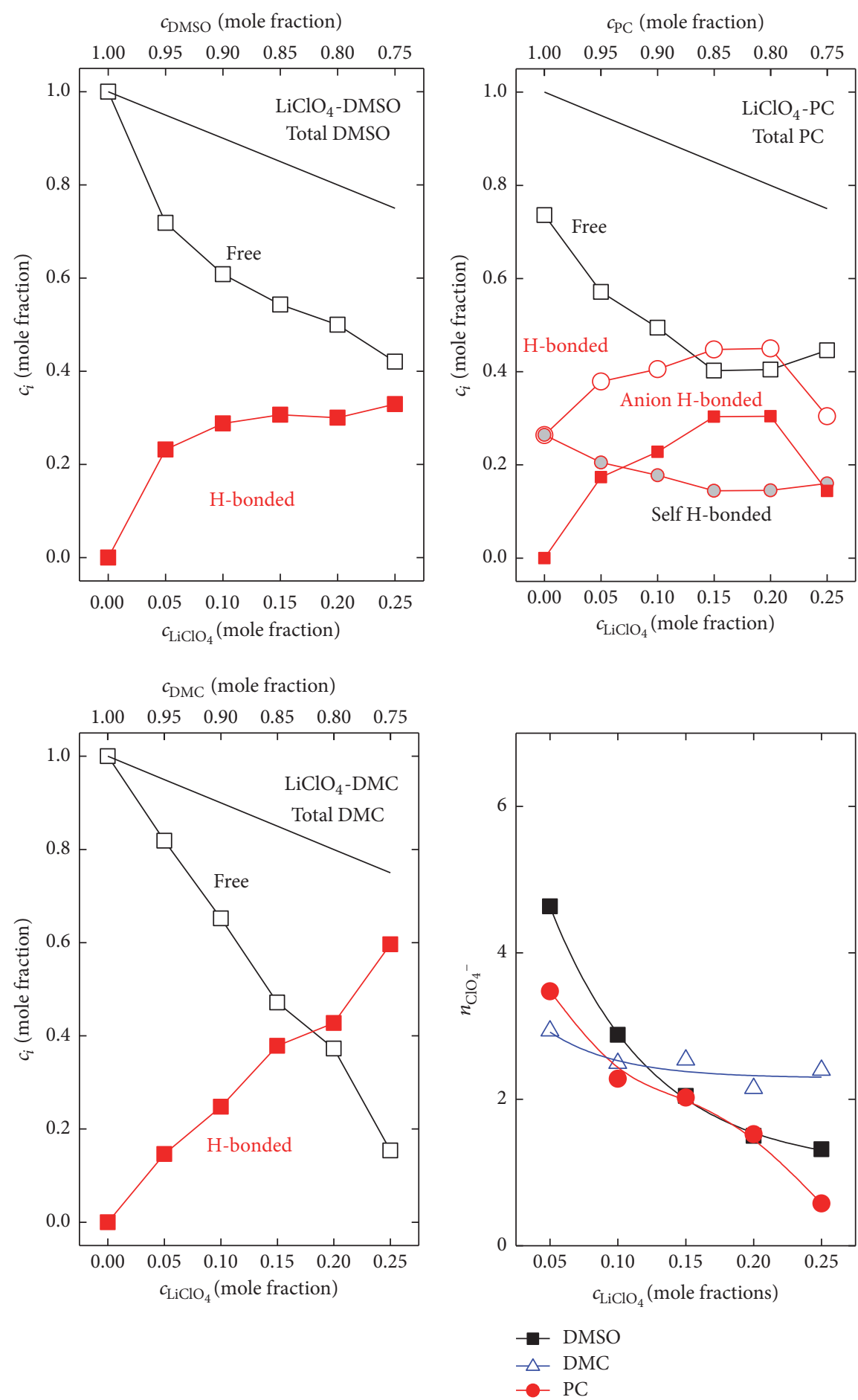

Figure 5: Concentration dependence of the amount of free and H-bonded molecules and mean number of the solvent molecules bonded to anions of the solvent in ionic solutions of DMSO, PC, and DMC.

concentration of SSIPs as DMC $>$ PC $>$ DMSO, which perfectly coincide with the order of solvents for increasing conductivity. It has been stressed in [5] that our conclusion is the first proof of the Fuoss theory [48], which states that SSIPs do contribute to conductance current.

The absence of solvated anions in $\mathrm{LiClO}_{4}-\mathrm{PC}$ and $\mathrm{LiClO}_{4}$-DMC systems, unlike $\mathrm{LiClO}_{4}$-DMSO system, cannot be explained by the values of solvent dielectric permittivity, since DMSO and PC have a much higher dielectric permittivity than DMC (Table 3). Probably, donor numbers rule the game, since the donor number of DMSO is almost twice as much as those of PC and DMC (Table 3).

3.3. Spectroscopic Signatures of Ion Pairing: Vibrational Dynamics. An additional opportunity enabling one to explain 


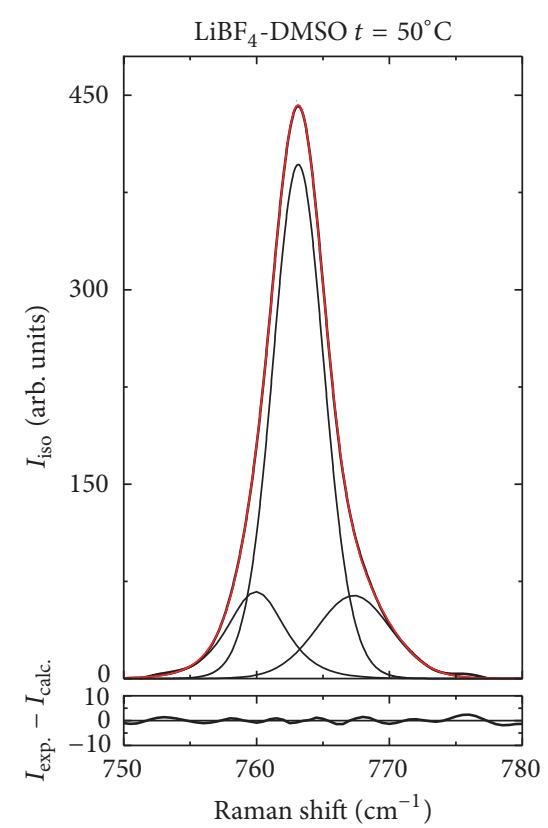

FIGURE 6: Free anions and ion pairs in the spectrum of the totally symmetric $v_{1}\left(\mathrm{~A}_{1}\right)$ vibration of $\mathrm{BF}_{4}{ }^{-}$in the DMSO solution containing 0.15 mole fractions of $\mathrm{LiBF}_{4}$.

TABLE 3: Dielectric permittivity $\varepsilon$ and donor numbers DN for DMSO, PC, and DMC.

\begin{tabular}{lccc}
\hline & DMSO & PC & DMC \\
\hline$\varepsilon$ & $47.24[11]$ & $64.92[2]$ & $3.107[2]$ \\
DN & $29.8[16]$ & $15.1[51]$ & $17.2[51]$ \\
\hline
\end{tabular}

the absence of free ions in solutions of lithium salts in carbonate solvents and to prove the statement that the charge transfer in carbonate solutions is caused by SSIPs is an analysis of vibrational dynamics in the systems studied. To do so one has to use an approach based on time-correlation functions (TCFs) of vibrational dephasing described in detail in $[42,43]$. TCFs $G(t)$ can be obtained by means of Fourier transforms of Raman spectra $I(v)$ :

$$
G(t)=\int_{-\infty}^{+\infty} I(\nu) \exp (2 \pi i c \nu t) d \nu,
$$

where $c$ is the speed of light. It is usually considered that the main cause of line broadening in Raman is the so-called vibrational dephasing. Interactions of a particle with its environment (perturbations) lead to time-dependent changes (modulation) of the particle's vibrational frequency $\Delta \omega=f(t)$ and to vibrational phase shifts. If $\omega$ is exponentially changing in time, $G_{\omega}(t)=\exp \left(-t / \tau_{\omega}\right)$, where $\tau_{\omega}$ is the modulation time, and the TCF of vibrational dephasing can be expressed by the Kubo equation

$$
G(t)=M_{2} \tau_{\omega}^{2} e^{-\exp \left(-t / \tau_{\omega}\right)-1+t / \tau_{\omega}},
$$

where $M_{2}=\int v^{2} I(v) d v / \int I(v) d v$ is the second vibrational moment (perturbation dispersion). As follows from existing theories (for details see $[42,43]$ ), the modulation time is usually considered equal to the time between collisions in liquids, $\tau_{\omega}=\tau_{\mathrm{BC}}$. Depending on perturbations TCF and the spectrum are changing. If $\tau_{\omega} \rightarrow 0$ (moveable environment of a particle, weak perturbations, and nonspecific interactions) TCFs are exponential and the spectra are of Lorentzian form. If $\tau_{\omega} \rightarrow \infty$ (interactions are strong, specific, and directed; molecule and its environment form a rigid quasilattice) TCFs and the spectra become Gaussian. Another parameter of the process is the dephasing time determined as the integral over $G(t), \tau_{V}=\int G(t) d t$.

Calculations have been performed by the method suggested in $[42,43]$ according to which (2) can be Fourier transformed analytically giving $G(t)$ in the following form:

$$
G(t)=\exp \left\{\frac{-\left[\left(t^{2}+\tau_{1}^{2}\right)^{1 / 2}-\tau^{1}\right]}{\tau_{2}}\right\} .
$$

Once $\tau_{1}$ and $\tau_{2}$ are known, $G(t)$ can be built, fit to Kubo equation (5), and analyzed. In Figure 8, representative TCFs for the free anions, SSIPs, and CIPs are shown. Their behavior is very characteristic. It appears that dephasing times in free anions are short. In SSIPs, $\tau_{V}$ become longer, and respective TCFs "cover" the TCFs of free ions. In CIPs, $\tau_{V}$ become shorter and respective TCFs remain under the envelope of the TCFs of SSIPs.

The analysis of modulation times appears even more straightforward (Table 4). In free anions, $\tau_{\omega}$ are short and evidence weak interactions between anions and their environment (solvent molecules). In SSIPs, $\tau_{\omega}$ are an order of magnitude longer thus signifying strong interactions between anions and cations. In CIPs showing up in more concentrated solutions, $\tau_{\omega}$ become shorter than in SSIPs, probably 


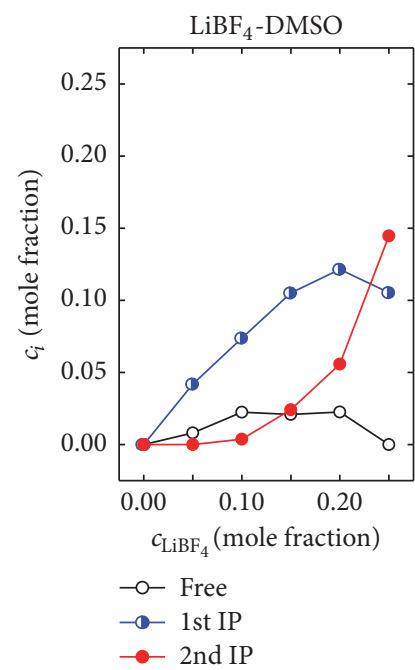

(a)

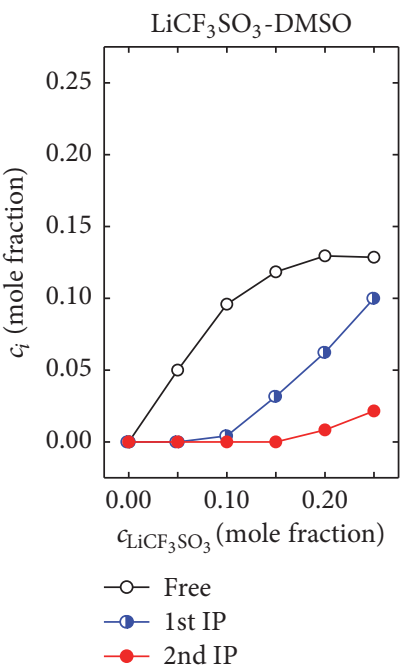

(b)

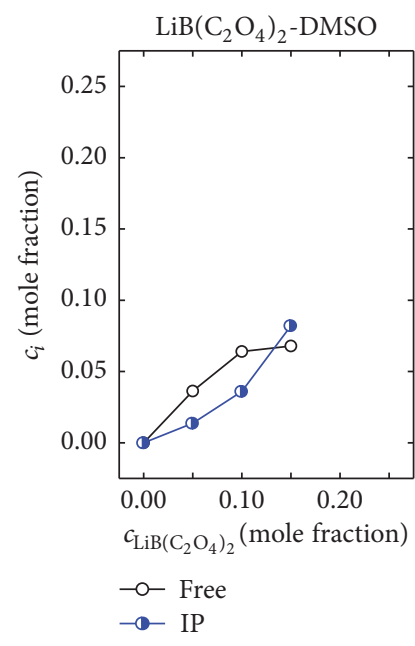

(c)

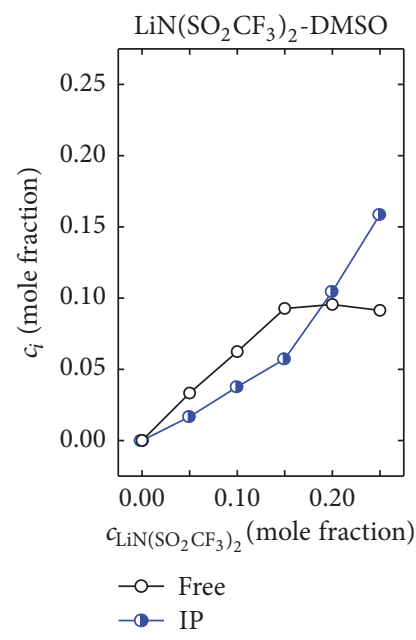

(d)

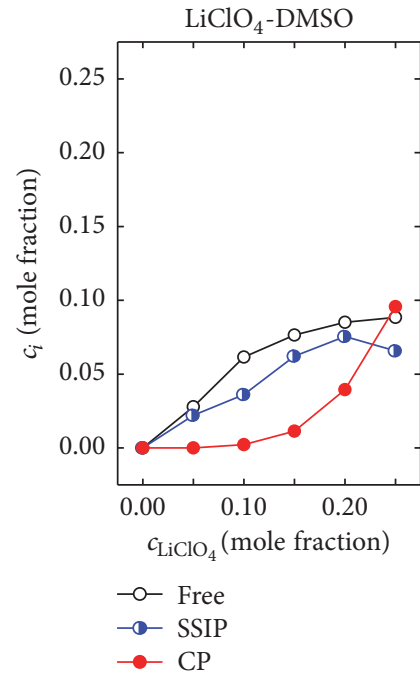

(e)

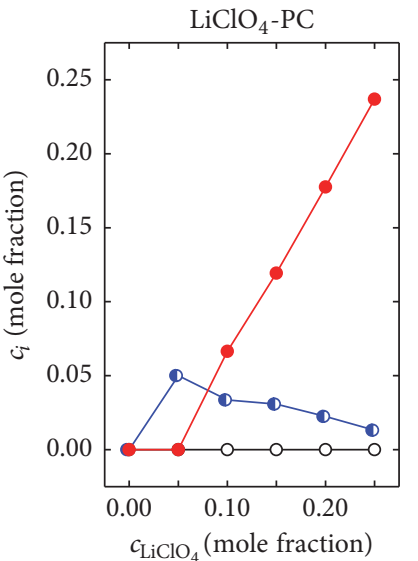

Assignment 1 Assignment 2

$\rightarrow$ - Free $\quad \longrightarrow$ - Free

$\rightarrow 1$ st IP $\rightarrow$ SSIP $\rightarrow \mathrm{CP}$

(f)

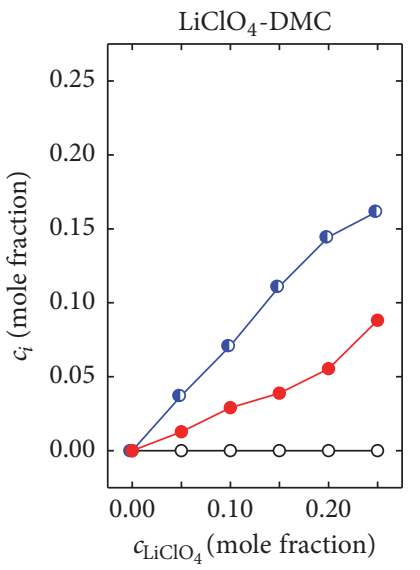

Assignment 1 Assignment 2

$\rightarrow-$ Free $\quad-0$ - Free

$\rightarrow 1$ st IP $\rightarrow$ SSIP

(g)

FIGURE 7: Concentrations of free anions and ion pairs in solutions of DMSO, PC, and DMC.

demonstrating that the structure of concentrated solutions acquires the features of molten salts, for which short $\tau_{\omega}$ are quite obvious [49]. This proves our conjectures regarding the nature of charge carriers in carbonate solvents. A more detailed description of these results will be given in our forthcoming papers.

\section{Conclusion}

In this paper, a brief overview of our Raman studies of cation and anion solvation and ion pairing in DMSO, PC, and DMC solutions of lithium salts, namely, tetrafluoroborate, perchlorate, nitrate, bis(oxalato) borate, trifluoromethylsulfonate, and bis(trifluoromethylsulfonyl) imide, is presented. Special attention is paid to differences in our and existing data and concepts. As indicated from our data, low cation solvation numbers $(\sim 2)$ in solutions disagree with previous measurements. This discrepancy is shown to arise from correct accounting for possible equilibria in the solvents studied, like dimerization (DMSO and PC), hydrogen bonding (PC), and conformation equilibria (DMC), disregarded in early studies. This unforeseen result has some analogies in molecular dynamics simulations of ionic solvation and probably calls for a reconsideration of existing data on solvation numbers. Another disputable question touches upon the absence of free ions in solutions of lithium salts in carbonate solvents and the statement that the charge transfer in carbonate solutions is caused by SSIPs. In order to support this conclusion, donor numbers have been analyzed, which in PC and DMC are as twice as high as those in DMSO. This means that solvation effects prevail in DMSO, whereas, in $\mathrm{PC}$ and $\mathrm{DMC}$, ion pairing is being brought to the fore. Furthermore, differences in the concentrations of CIPs in solutions of different salts can be understood in terms of 
TABLE 4: Relaxation $\tau_{V}$ and modulation $\tau_{\omega}$ times for $\mathrm{Cl}-\mathrm{O}$ vibrations of $\mathrm{ClO}_{4}{ }^{-}$anion in ionic solutions of DMSO, PC and DMC.

\begin{tabular}{|c|c|c|c|c|c|c|}
\hline \multirow{2}{*}{ c, m.f. } & \multicolumn{2}{|c|}{$\mathrm{LiClO}_{4}-\mathrm{DMSO}$} & \multicolumn{2}{|c|}{$\mathrm{LiClO}_{4}-\mathrm{DMC}$} & \multicolumn{2}{|c|}{$\mathrm{LiClO}_{4}-\mathrm{PC}$} \\
\hline & $\tau_{V}, \mathrm{ps}$ & $\tau_{\omega}, \mathrm{ps}$ & $\tau_{V}, \mathrm{ps}$ & $\tau_{\omega}, \mathrm{ps}$ & $\tau_{V}, \mathrm{ps}$ & $\tau_{\omega}$,ps \\
\hline \multicolumn{7}{|c|}{ Free anion } \\
\hline 0.05 & $2.17^{\mathrm{a}}$ & $0.710^{\mathrm{b}}$ & & & & \\
\hline 0.1 & $2.10^{\mathrm{a}}$ & $0.782^{\mathrm{b}}$ & & & & \\
\hline 0.15 & $1.90^{\mathrm{a}}$ & $0.463^{\mathrm{b}}$ & & & & \\
\hline 0.2 & $1.64^{\mathrm{a}}$ & $0.249^{\mathrm{b}}$ & & & & \\
\hline 0.25 & $1.41^{\mathrm{a}}$ & $0.162^{\mathrm{b}}$ & & & & \\
\hline \multicolumn{7}{|c|}{ Anion in SSIP } \\
\hline 0.05 & $3.91^{\mathrm{a}}$ & $9.25^{\mathrm{b}}$ & $1.4 \pm 0.2$ & $9 \pm 1$ & $2.7 \pm 0.3$ & $5.3 \pm 0.3$ \\
\hline 0.1 & $3.93^{\mathrm{a}}$ & $18.9^{\mathrm{b}}$ & $1.3 \pm 0.2$ & $9 \pm 1$ & $2.8 \pm 0.4$ & $7.2 \pm 0.4$ \\
\hline 0.15 & $3.53^{\mathrm{a}}$ & $10.8^{\mathrm{b}}$ & $1.3 \pm 0.2$ & $8 \pm 1$ & $2.9 \pm 0.4$ & $7.9 \pm 0.4$ \\
\hline 0.2 & $3.17^{\mathrm{a}}$ & $9.96^{\mathrm{b}}$ & $1.2 \pm 0.2$ & $6 \pm 1$ & $2.8 \pm 0.5$ & $9.7 \pm 0.5$ \\
\hline 0.25 & $3.08^{\mathrm{a}}$ & $10.9^{\mathrm{b}}$ & $1.1 \pm 0.2$ & $6 \pm 1$ & $2.8 \pm 0.5$ & $10.0 \pm 0.5$ \\
\hline \multicolumn{7}{|c|}{ Anion in CIP } \\
\hline \multicolumn{7}{|l|}{0.05} \\
\hline 0.1 & $3.0 \pm 0.3$ & $2.1 \pm 0.3$ & $1.0 \pm 0.2$ & $2.0 \pm 0.2$ & $0.76 \pm 0.04$ & $0.17 \pm 0.04$ \\
\hline 0.15 & $2.4 \pm 0.1$ & $7.3 \pm 0.6$ & $0.9 \pm 0.1$ & $0.8 \pm 0.1$ & $0.86 \pm 0.03$ & $0.23 \pm 0.05$ \\
\hline 0.2 & $1.75 \pm 0.02$ & $0.64 \pm 0.09$ & $0.9 \pm 0.1$ & $0.4 \pm 0.1$ & $0.84 \pm 0.03$ & $0.13 \pm 0.03$ \\
\hline 0.25 & $1.37 \pm 0.02$ & $0.25 \pm 0.04$ & $1.0 \pm 0.1$ & $0.35 \pm 0.05$ & $0.82 \pm 0.03$ & $0.13 \pm 0.03$ \\
\hline
\end{tabular}

${ }^{\mathrm{a}}$ Less than $1 \%$ uncertainty. ${ }^{\mathrm{b}}$ Less than $2 \%$ uncertainty.

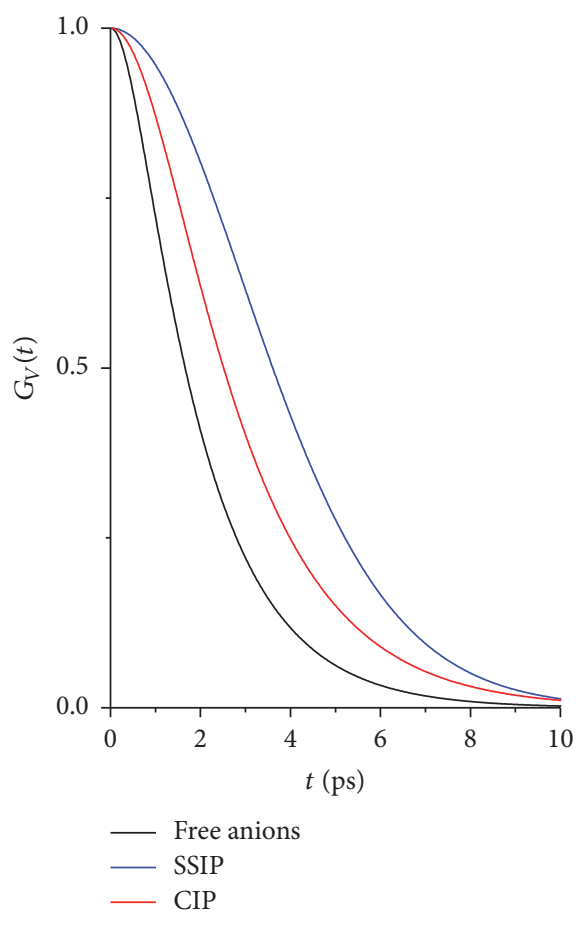

FIGURE 8: Representative time-correlation functions of dephasing of $\mathrm{ClO}_{4}{ }^{-}$anion in free state, SSIP, and CIP in the DMSO solution containing 0.1 mole fractions of $\mathrm{LiClO}_{4}$.

ion pair dissociation energies obtained by means of quantum chemical calculations. Even more direct proofs of the nature of charge carriers in carbonate solvents have been obtained by means of analyses of vibrational dynamics. It has been found that modulation (collision) times for free anions are short and evidence weak interactions between anions and solvent molecules. In SSIPs, $\tau_{\omega}$ are an order of magnitude longer thus signifying strong interactions between anions and cations. In CIPs, $\tau_{\omega}$ become shorter than in SSIPs reflecting the transformation of the structure of concentrated solutions to that of molten salts.

\section{Competing Interests}

The authors declare no conflict of interests.

\section{Acknowledgments}

M. B. Ataev and M. M. Gafurov were supported by the Russian Federation Basic Research Fund (Grant no. 13-0300384A) and the Ministry of Education and Science of the Russian Federation (State Contract no. 16.552.11.7092).

\section{References}

[1] J. M. Alía, "Raman spectroscopic studies of ion-ion interactions in aqueous and nonaqueous electrolyte solutions," in Handbook of Raman Spectroscopy, From the Research Laboratory to the Process Line, I. R. Lewis and H. G. M. Edward, Eds., pp. 617683, Marcel Dekker, New York, NY, USA, 2001.

[2] K. Xu, "Nonaqueous liquid electrolytes for lithium-based rechargeable batteries," Chemical Reviews, vol. 104, no. 10, pp. 4303-4417, 2004.

[3] S. A. Kirillov, M. I. Gorobets, D. O. Tretyakov, M. B. Ataev, and M. M. Gafurov, "Phase diagrams and conductivity of lithium salt systems in dimethyl sulfoxide, propylene carbonate and 
dimethyl carbonate," Journal of Molecular Liquids, vol. 205, pp. 78-84, 2015.

[4] M. I. Gorobets, M. B. Ataev, M. M. Gafurov, and S. A. Kirillov, "Raman study of solvation in solutions of lithium salts in dimethyl sulfoxide, propylene carbonate and dimethyl carbonate," Journal of Molecular Liquids, vol. 205, pp. 98-109, 2015.

[5] S. A. Kirillov, M. M. Gafurov, M. I. Gorobets, and M. B. Ataev, "Raman study of ion pairing in solutions of lithium salts in dimethyl sulfoxide, propylene carbonate and dimethyl carbonate," Journal of Molecular Liquids, vol. 199, pp. 167-174, 2014.

[6] M. M. Gafurov, S. A. Kirillov, M. I. Gorobets et al., "Phase equilibria and ionic solvation in the lithium tetrafluoroboratedimethylsulfoxide system," Journal of Applied Spectroscopy, vol. 81, no. 6, pp. 912-918, 2015.

[7] M. M. Gafurov, M. B. Ataev, K. S. Rabadanov et al., "Solvation of $\mathrm{LiBF}_{4}$ ions in dimethyl sulfoxide solutions according to Raman spectroscopy data," Russian Journal of Physical Chemistry A, vol. 89, no. 4, pp. 639-643, 2015.

[8] M. Balaish, A. Kraytsberg, and Y. Ein-Eli, "A critical review on lithium-air battery electrolytes," Physical Chemistry Chemical Physics, vol. 16, no. 7, pp. 2801-2822, 2014.

[9] M. J. Trahan, S. Mukerjee, E. J. Plicht, M. A. Hendrickson, and K. M. Abraham, "Studies of li-air cells utilizing dimethyl sulfoxidebased electrolyte," Journal of the Electrochemical Society, vol. 160, no. 2, pp. A259-A267, 2013.

[10] Q. Yu and S. Ye, "In situ study of oxygen reduction in dimethyl sulfoxide (DMSO) solution: a fundamental study for development of the lithium-oxygen battery," The Journal of Physical Chemistry C, vol. 119, no. 22, pp. 12236-12250, 2015.

[11] S. A. Kirillov, M. I. Gorobets, M. M. Gafurov, M. B. Ataev, and K. S. Rabadanov, "Self-association and picosecond dynamics in liquid dimethyl sulfoxide," Journal of Physical Chemistry B, vol. 117, no. 32, pp. 9439-9448, 2013.

[12] S. A. Kirillov, M. I. Gorobets, M. M. Gafurov, K. S. Rabadanov, and M. B. Ataev, "Temperature dependence of associative equilibria of DMSO according to Raman scattering spectra," Russian Journal of Physical Chemistry A, vol. 88, no. 1, pp. 175177, 2014.

[13] L. Gontrani, O. Russina, F. C. Marincola, and R. Caminiti, "An energy dispersive $\mathrm{x}$-ray scattering and molecular dynamics study of liquid dimethyl carbonate," Journal of Chemical Physics, vol. 131, no. 24, Article ID 244503, 2009.

[14] A. Brodin and P. Jacobsson, "Dipolar interaction and molecular ordering in liquid propylene carbonate: anomalous dielectric susceptibility and Raman non-coincidence effect," Journal of Molecular Liquids, vol. 164, no. 1-2, pp. 17-21, 2011.

[15] Y. Wang and P. B. Balbuena, "Associations of alkyl carbonates: intermolecular C-H..O interactions," Journal of Physical Chemistry A, vol. 105, no. 43, pp. 9972-9982, 2001.

[16] A. A. Kloss and W. R. Fawcett, "ATR-FTIR studies of ionic solvation and ion-pairing in dimethyl sulfoxide solutions of the alkali metal nitrates," Journal of the Chemical Society, Faraday Transactions, vol. 94, no. 11, pp. 1587-1591, 1998.

[17] J. M. Alía and H. G. M. Edwards, "Ion solvation and ion association in lithium trifluoromethanesulfonate solutions in three aprotic solvents. An FT-Raman spectroscopic study," Vibrational Spectroscopy, vol. 24, no. 2, pp. 185-200, 2000.

[18] Z. Wang, B. Huang, S. Wang, R. Xue, X. Huang, and L. Chen, "Vibrational spectroscopic study of the interaction between lithium perchlorate and dimethylsulfoxide," Electrochimica Acta, vol. 42, no. 17, pp. 2611-2617, 1997.

[19] X. Xuan, J. Wang, Y. Zhao, and J. Zhu, "Experimental and computational studies on the solvation of lithium tetrafluorobrate in dimethyl sulfoxide," Journal of Raman Spectroscopy, vol. 38, no. 7, pp. 865-872, 2007.

[20] D. Battisti, G. A. Nazri, B. Klassen, and R. Aroca, "Vibrational studies of lithium perchlorate in propylene carbonate solutions," Journal of Physical Chemistry, vol. 97, no. 22, pp. 5826-5830, 1993.

[21] T. Li and P. B. Balbuena, "Theoretical studies of lithium perchlorate in ethylene carbonate, propylene carbonate, and their mixtures," Journal of the Electrochemical Society, vol. 146, no. 10, pp. 3613-3622, 1999.

[22] P. A. Brooksby and W. R. Fawcett, "Infrared (attenuated total reflection) study of propylene carbonate solutions containing lithium and sodium perchlorate," Spectrochimica Acta Part A: Molecular and Biomolecular Spectroscopy, vol. 64, no. 2, pp. 372382, 2006.

[23] X. Xuan, J. Wang, J. Tang, G. Qu, and J. Lu, "A vibrational spectroscopic study of ion solvation in lithium perchlorate/propylene carbonate electrolyte," Physics and Chemistry of Liquids, vol. 39, no. 3, pp. 327-342, 2001.

[24] H. Tsunekawa, A. Narumi, M. Sano, A. Hiwara, M. Fujita, and H. Yokoyama, "Solvation and ion association studies of $\mathrm{LiBF}_{4}$ propylenecarbonate and $\mathrm{LiBF}_{4}$-propylenecarbonate-trimethyl phosphate solutions," Journal of Physical Chemistry B, vol. 107, no. 39, pp. 10962-10966, 2003.

[25] K. Kondo, M. Sano, A. Hiwara et al., "Conductivity and solvation of $\mathrm{Li}^{+}$ions of $\mathrm{LiPF}_{6}$ in propylene carbonate solutions," Journal of Physical Chemistry B, vol. 104, no. 20, pp. 5040-5044, 2000.

[26] L. Doucey, M. Revault, A. Lautié, A. Chaussé, and R. Messina, "A study of the $\mathrm{Li} / \mathrm{Li}^{+}$couple in DMC and PC solvents. Part 1: characterization of $\mathrm{LiAsF}_{6} / \mathrm{DMC}$ and $\mathrm{LiAsF}_{6} / \mathrm{PC}$ solutions," Electrochimica Acta, vol. 44, no. 14, pp. 2371-2377, 1999.

[27] K. Wakabayashi, Y. Maeda, K. Ozutsumi, and H. Ohtaki, "The structure of solvated halide ions in dimethyl sulfoxide studied by Raman spectroscopy and X-ray diffraction," Journal of Molecular Liquids, vol. 110, no. 1-3, pp. 43-50, 2004.

[28] M. I. S. Sastry and S. Singh, "Raman spectral studies of solutions of alkali metal perchlorates in dimethyl sulfoxide and water," Canadian Journal of Chemistry, vol. 63, no. 7, pp. 1351-1356, 1985.

[29] M. Chabanel, D. Legoff, and K. Touaj, "Aggregation of perchlorates in aprotic donor solvents. Part 1-lithium and sodium perchlorates," Journal of the Chemical Society, Faraday Transactions, vol. 92, pp. 4199-4205, 1996.

[30] I. S. Perelygin and G. P. Mikhailov, "Appearance of ion-ion interactions in the Raman scattering spectra of the perchlorate ion," Journal of Applied Spectroscopy, vol. 49, no. 1, pp. 713-717, 1988.

[31] R. Wooldridge, M. Fisher, G. Ritzhaupt, and J. P. Devlin, "Dependence of ion pairing and solvation on solution temperature: evidence from DMSO solution and matrix-solvation spectra," The Journal of Chemical Physics, vol. 86, no. 8, pp. 43914395, 1987.

[32] I. S. Perelygin and G. P. Mikhailov, "Manifestations of ion-ion interactions in the Raman spectra of the nitrate ion," Journal of Applied Spectroscopy, vol. 48, no. 5, pp. 516-521, 1988.

[33] J. M. Alia and H. G. M. Edwards, "FT-Raman study of ionic interactions in lithium and silver tetrafluoroborate solutions in 
acrylonitrile," Journal of Solution Chemistry, vol. 29, no. 9, pp. 781-797, 2000.

[34] I. S. Perelygin and M. A. Klimchuk, "Manifestations of interionic interactions in the IR absorption spectra of the tetrafluoroborate ion," Journal of Applied Spectroscopy, vol. 50, no. 2, pp. 207-211, 1989.

[35] P. Johansson, S. P. Gejji, J. Tegenfeldt, and J. Lindgren, "The imide ion: potential energy surface and geometries," Electrochimica Acta, vol. 43, no. 10-11, pp. 1375-1379, 1998.

[36] M. Herstedt, M. Smirnov, P. Johansson et al., "Spectroscopic characterization of the conformational states of the bis(trifluoromethanesulfonyl)imide anion $\left(\mathrm{TFSI}^{-}\right)$," Journal of Raman Spectroscopy, vol. 36, no. 8, pp. 762-770, 2005.

[37] I. Rey, P. Johansson, J. Lindgren, J. C. Lassègues, J. Grondin, and L. Servant, "Spectroscopic and theoretical study of $\left(\mathrm{CF}_{3} \mathrm{SO}_{2}\right)_{2} \mathrm{~N}^{-}\left(\mathrm{TFSI}^{-}\right)$and $\left(\mathrm{CF}_{3} \mathrm{SO}_{2}\right)_{2} \mathrm{NH}$ (HTFSI)," The Journal of Physical Chemistry A, vol. 102, no. 19, pp. 3249-3258, 1998.

[38] S. P. Gejji, C. H. Suresh, K. Babu, and S. R. Gadre, "Ab initio structure and vibrational frequencies of $\left(\mathrm{CF}_{3} \mathrm{SO}_{2}\right)_{2} \mathrm{~N}^{-} \mathrm{Li}^{+}$ion pairs," Journal of Physical Chemistry A, vol. 103, no. 37, pp. 74747480, 1999.

[39] R. Holomb, W. Xu, H. Markusson, P. Johansson, and P. Jacobsson, "Vibrational spectroscopy and ab initio studies of lithium bis(oxalato)borate (LiBOB) in different solvents," Journal of Physical Chemistry A, vol. 110, no. 40, pp. 11467-11472, 2006.

[40] Z. Wang, W. Gao, X. Huang, Y. Mo, and L. Chen, "Spectroscopic studies on interactions and microstructures in propylene carbonate-LiTFSI electrolytes," Journal of Raman Spectroscopy, vol. 32, no. 11, pp. 900-905, 2001.

[41] I. S. Perelygin and M. A. Klimchuk, "Manifestations of interionic interactions in IR spectra of the trifluoromethanesulfonate ion," Journal of Applied Spectroscopy, vol. 55, no. 3, pp. 855-859, 1991.

[42] S. A. Kirillov, "Novel approaches in spectroscopy of interparticle interactions. vibrational line profiles and anomalous noncoincidence effects," in Novel Approaches to the Structure and Dynamics of Liquids: Experiments, Theories and Simulations, J. Samios and V. Durov, Eds., NATO ASI Series, pp. 193-227, Kluwer, Dordrecht, Netherland, 2004.

[43] S. A. Kirillov, "Spectroscopy of interparticle interactions in ionic and molecular liquids: novel approaches," Pure and Applied Chemistry, vol. 76, no. 1, pp. 171-181, 2004.

[44] M.-T. Forel and M. Tranquille, "Spectres de vibration du diméthylsulfoxyde et dn diméthylsulfoxyde- $\mathrm{d}_{6}$," Spectrochimica Acta Part A: Molecular Spectroscopy, vol. 26, no. 5, pp. 10231034, 1970.

[45] G. J. Janz, J. Ambrose, J. W. Coutts, and J. R. Downey Jr., "Raman spectrum of propylene carbonate," Spectrochimica Acta Part A: Molecular Spectroscopy, vol. 35, no. 2, pp. 175-179, 1979.

[46] J. E. Katon and M. D. Cohen, "The vibrational spectra and structure of dimethyl carbonate and its conformational behavior," Canadian Journal of Chemistry, vol. 53, no. 9, pp. 1378-1386, 1975.

[47] X. Guo, S. H. Tan, S. F. Pang, and Y. H. Zhang, "Measurement of the association constants through micro-Raman spectra of supersaturated lithium perchlorate droplets," Science China Chemistry, vol. 56, no. 11, pp. 1633-1640, 2013.

[48] R. M. Fuoss, "Conductance-concentration function for the paired ion model," Journal of Physical Chemistry, vol. 82, no. 22, pp. 2427-2440, 1978.
[49] S. A. Kirillov, "Interactions and picosecond dynamics in molten salts: a rewiew with comparison to molecular liquids," Journal of Molecular Liquids, vol. 76, no. 1-2, pp. 35-95, 1998.

[50] E. Jónsson and P. Johansson, "Modern battery electrolytes: ionion interactions in $\mathrm{Li}^{+} / \mathrm{Na}^{+}$conductors from DFT calculations," Physical Chemistry Chemical Physics, vol. 14, no. 30, pp. 1077410779, 2012.

[51] M. Takeuchi, N. Matubayasi, Y. Kameda, B. Minofar, S.-I. Ishiguro, and Y. Umebayashi, "Free-energy and structural analysis of ion solvation and contact ion-pair formation of $\mathrm{Li}^{+}$with $\mathrm{BF}_{4}^{-}$ and $\mathrm{PF}_{6}^{-}$in water and carbonate solvents," Journal of Physical Chemistry B, vol. 116, no. 22, pp. 6476-6487, 2012. 

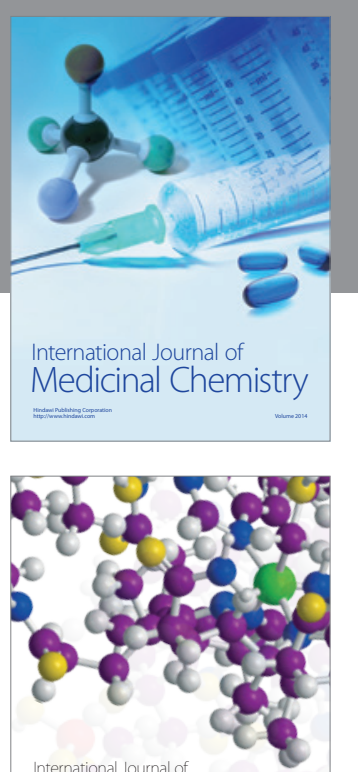

Carbohydrate Chemistry

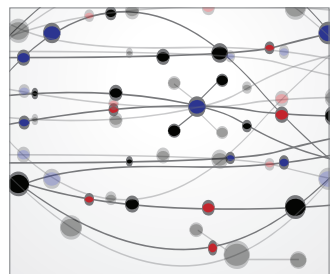

The Scientific World Journal
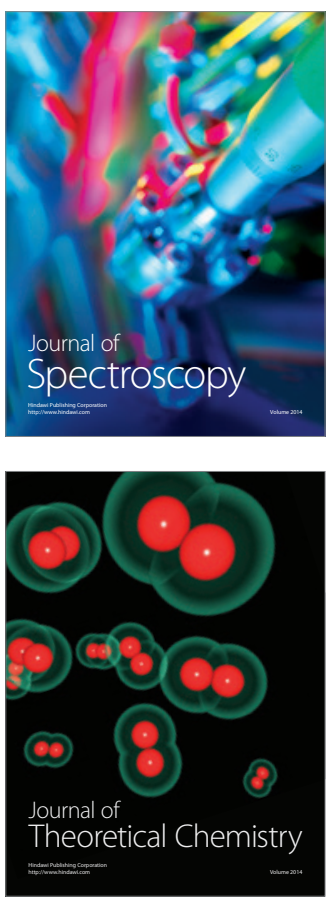
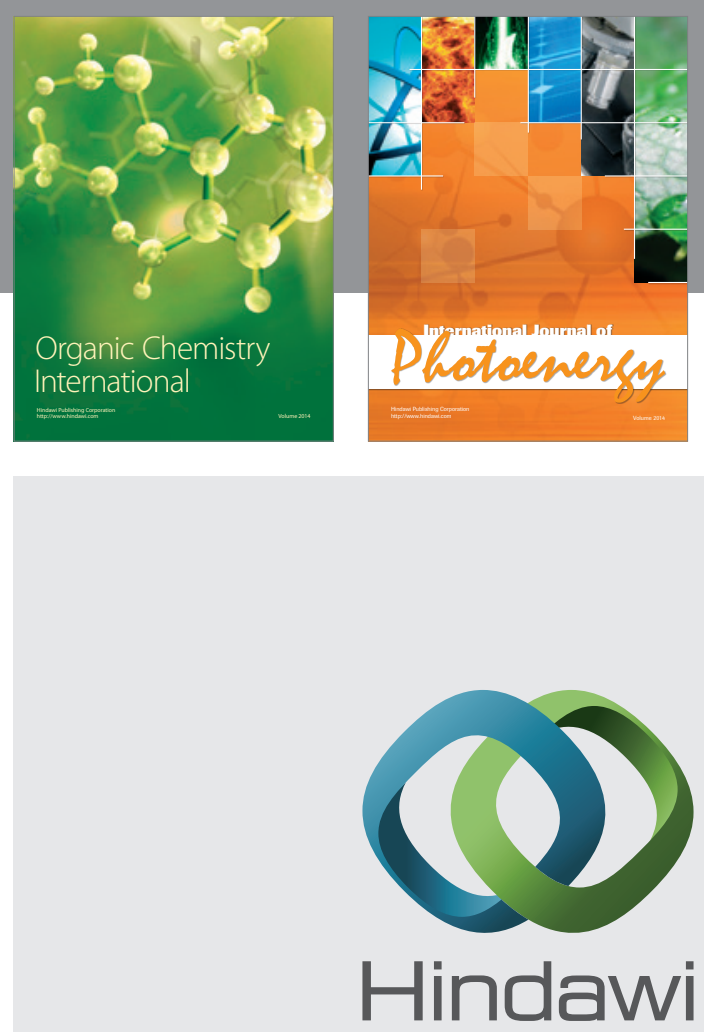

Submit your manuscripts at

http://www.hindawi.com

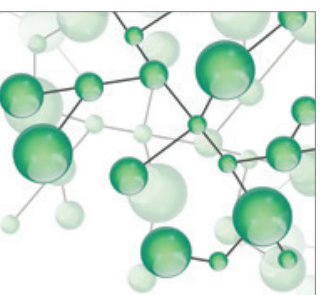

International Journal of

Inorganic Chemistry

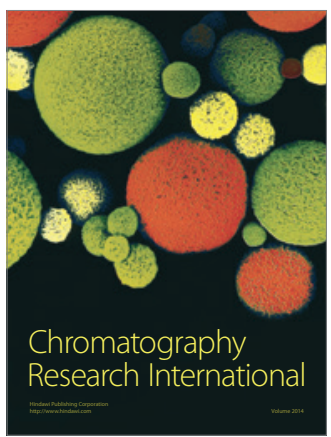

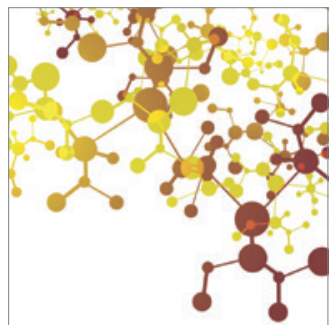

Applied Chemistry
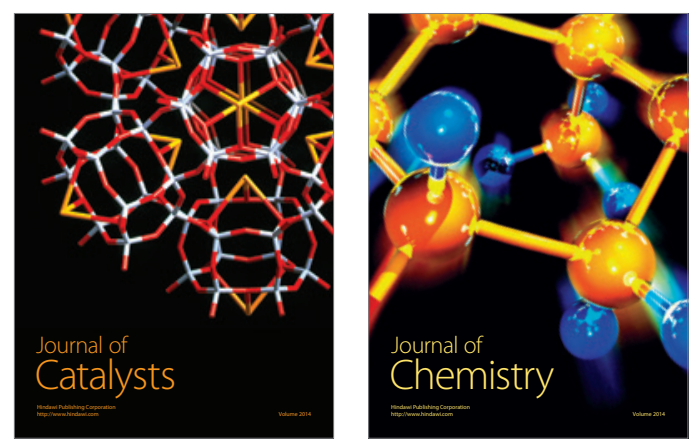
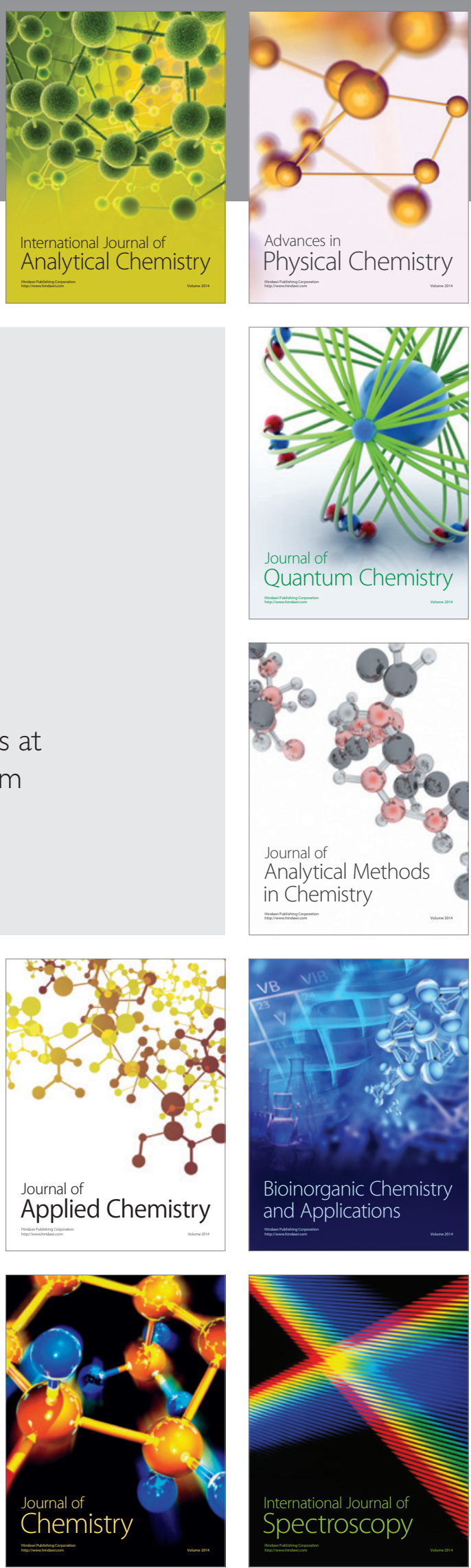